\title{
CONTROL STRATEGY AND EFFICIENCY OPTIMIZATION OF SWITCHED RELUCTANCE MOTOR
}

\author{
إستر اتيجية التحكم الأمثل فى محرك المماوقة المستمز
}

\section{By}

\section{M. I. EL-SHAMOTY}

\section{DEPARTMENT OF ELECTRICAL ENGINEERING, FACULTY OF ENGINEERING EL-MANSOURA UNIVERSITY, EL-MANSOURA, EGYPT}

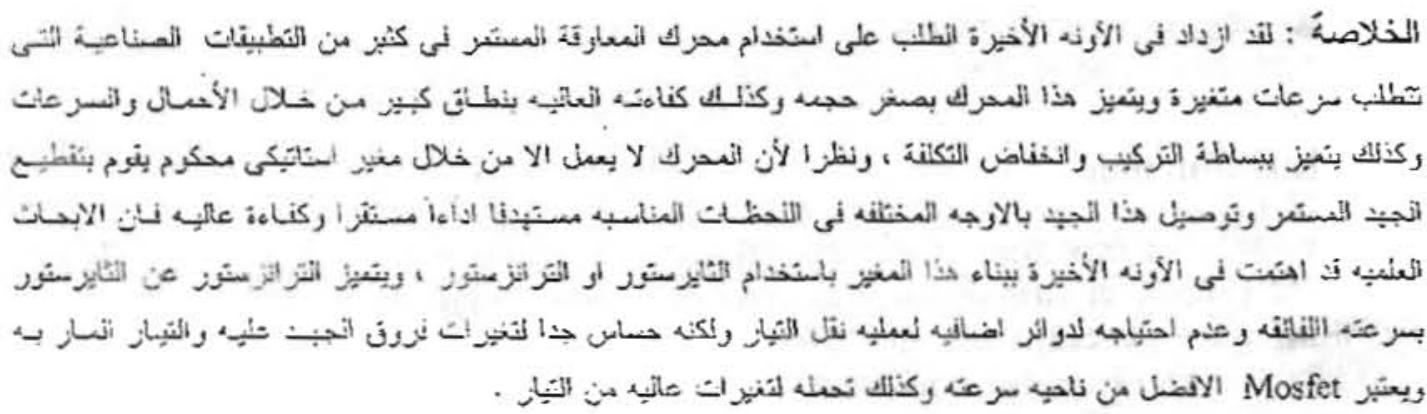

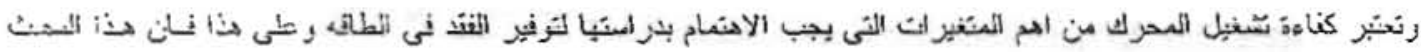

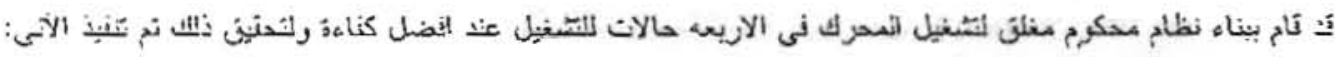

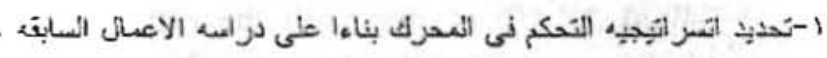

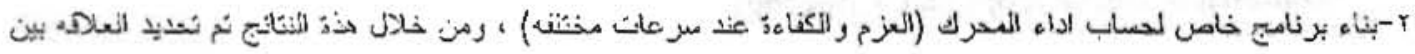

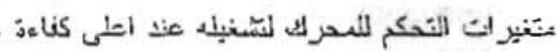

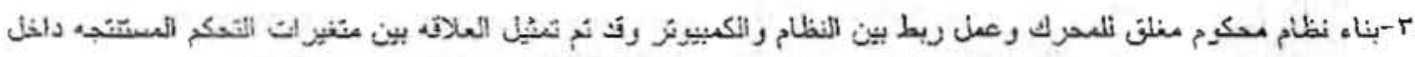

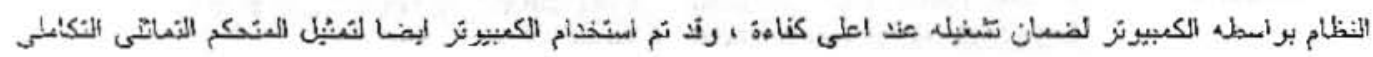

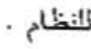

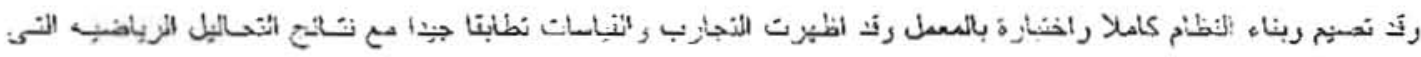

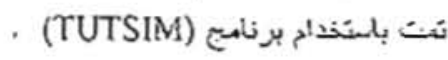

\begin{abstract}
The switched reluctance motor (SRM) has attracted world-wide interest as a new industrial drive. The attractive features of this machine are its compactness and simplicity. Efficiency is an important factor when handling power in the drive system of such motor. There fore, the aim of the closed loop control strategy presented by this paper is to drive the switched reluctance motor at optimum efficiency. This can be achieved by a proper choice of the best combination of control variables which ensure highest efficiency over a vide-range of speed and torque.
\end{abstract}


The decision about the best combination is based on the analysis of resuits obtained by a modeling computer prograrn. This program is written to simulate the 3 -phase, $1.1 \mathrm{~kW}, 800$ R.P.M. prototype model aiready built in El-Mansoura Electrical Machine Laboratory [1]. It calculates the motor performance: average torque, efficiency and the instantaneous phase current over a wide-range of speed. The carried out analysis gave the best combination of control variables and a simple relationship between them. They had been limited to be the switch-on angle $\left(\theta_{0 n}\right)$ and the conduction-angle $\left(\theta_{c}\right)$.

The integrated drive system, including the relevant controllers, has been built and tested. Microcomputer steering of the command signals with speed and rotor position feedback is applied. The deduced relationship between $\theta_{\text {on }}$ and $\theta_{c}$ is implemented in the control loop, simulating the basic feature of the proposed control strategy.

The comparison between the measured and calculated wave-forms of the instantaneous phase current shows a good concordance. In addition, steady operation is attained.

\section{Introduction}

The use of a new type of variable reluctance stepping motor, called switched reluctance motor (SRM), in conjunction with electronic devices leads to a new speed drive system. A SRM with electrically switched stator windings can be used as a variable speed drive. It tends to exhibit characteristics similar to a series dc motor. Its speed can be controlled over a wide range by controlling the switching parameters. Modern power semiconductor switching devices, such as the power transistor and the gate turn-off thyristor are now capable of bringing out the optimum performance from such type of motors. Position sensors feed rotor position information to an electronic controller which automatically maintains the stator $\mathrm{mmf}$ excitation pattern in step with the rotating rotor, ensuring optimum torque production. Additional feedback loops can adjust the nature of the inherent speed torque characteristics.

The SRM is a kind of stepping motor. It is essentially an electromechanical drive in which both stator and rotor are slotted and torque is developed by magnetic forces between particular stator and rotor teeth. Rotation is produced by sequential switching of the pattern of mmf applied to the stator teeth. Excitation is only on the stator side, and the rotor has no windings or bars. Simple concentrated stator coils are wound around main poles, with diametrically opposite windings connected in series to form a single phase. The basic elements of a doubly-salient two-pole reluctance motor are shown in Fig. 1a where the corresponding variation of inductance with rotor position and the torque produced for the pair of stator poles are depicted in Fig. Ib. In this figure only two of a larger number of stator poles are included. During movement of the rotor-poles under the stator-poles the reluctance of the magnetic circuit will vary and therefore the inductance of the phase-winding. A complete cycle of the varying inductance occurs over the angular-displacement regions R1 through RS, which is equal to a rotor pole-pitch. The number of cycies of inductance variation per revolution is proportional to the number of rotor pole pairs. The cycle of the varying inductance, shown in Fig. $1 \mathrm{~b}$ represents the so called "ideal inductance pattern"[2]. 


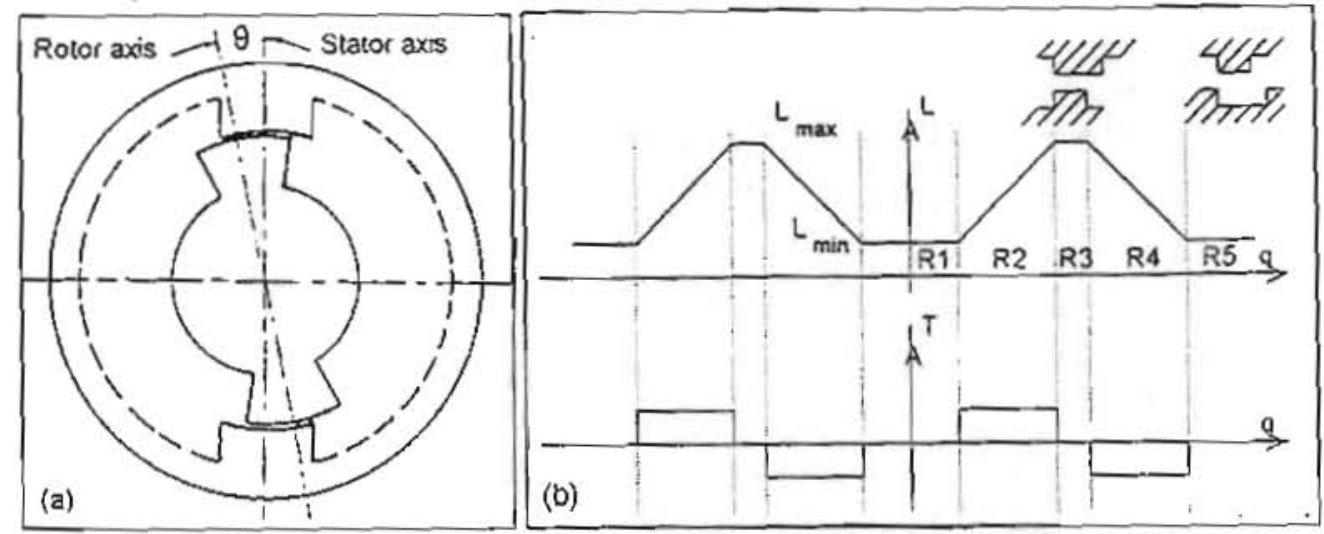

Fig. I Basic elements, Inductance variation, and torque variation in SRM

Torque is deveioped by the tendency for the magnetic circuit to adopt a configuration of minimum reluctance (maximum inductance). The torque is independent of the direction of current flow so that unidirectional currents can be used, permitting a simplification of the electronic driving circuits. In general because of magnetic nonlinearities, the torque $\mathrm{T}$ must be calculated in terms of co-energy W' [3] as shown,

$\mathrm{T}(\theta, \mathrm{i})=\frac{\hat{o} \overline{\mathrm{W}}(\theta, \mathrm{i})}{\partial \theta}$

From Eq. 1, it is noted that changes in co-energy depend on both the angular position of the rotor and on the instantaneous value of the current. Proper allowance for both of these factors must be made in predicting performance, but by considering a simplified model (neglecting magnetic saturation and copper losses) Eq.1 can be simplified to [3] ;

$T(\theta, i)=\frac{i^{2}}{2} \cdot \frac{d L}{d \theta}$

So, The associated variation of torque for a constant coil current follows Eq.(2) and is shown in Fig. lb. The torque can be controlled to give a positive action (i.e. motor action) or a negative action (i.e. generator action) simply by switching the current in the coil on and off at appropriate instants during the inductance cycle.

\section{General Configuration Of The Drive System}

The overall configuration of the implemented system is shown in Fig.3.1. It can be divide into several parts; the SRM, the power circuit, and the control and measuring circuits.

\section{Power Circuit}

It consists of three parts; a constant voltage-source, a braking circuit, and a Mosfet inverter These three parts are shown in Figure 2. 


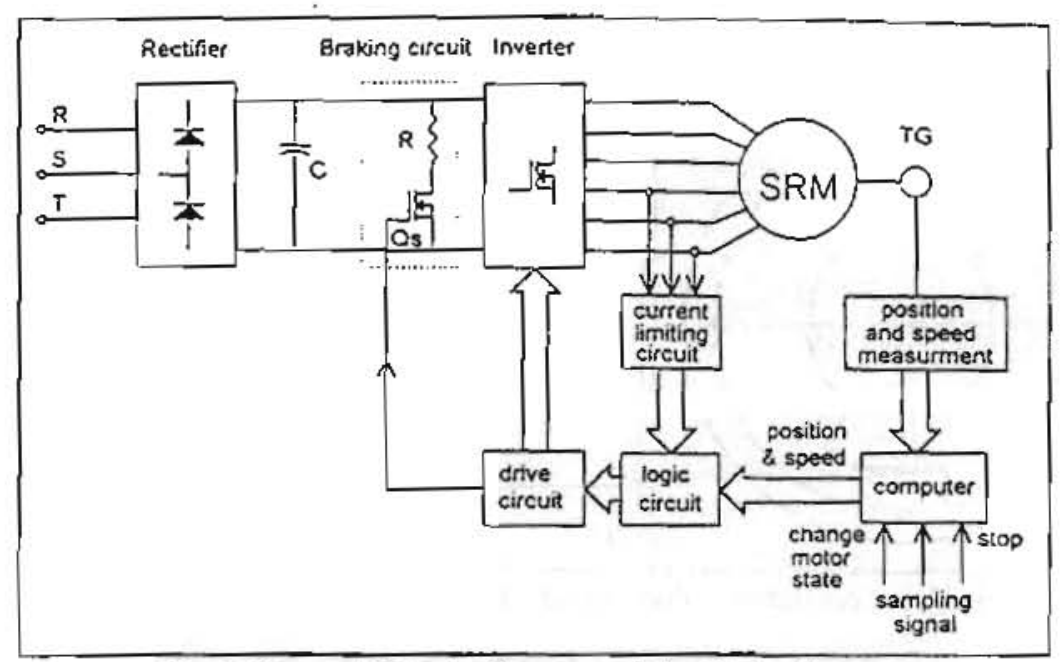

Fig.2 General Block-diagram of the Drive System

\section{A. Constant Voltage-Source}

The supply voltage is rectified using a three-phase diode bridge performing uncontrolled DC power-source. The output voltage is smoothed by a capacitor bank in order to get a DC constant voltage-source.

\section{B. Braking Circuit}

Because the power supply is made of a diode bridge and a shunt smoothing capacitor bank, the power supply does not able to be a sink for the returned energy which is generated when the motor is operated in the braking mode or in the freewheeling period. So, the capacitor bank will over-charged and exceeds the maximum allowable bus voltage. This voltage must be limited to a chosen value for safe mosfet operation. This can be done by connecting a braking resistor in series with a mosfet switch across the capacitor bank as shown in Fig.2. When the capacitor bank voltage exceeds a certain limit value, the mosfet will turned on and the braking resistor will be in parallel with the capacitor bank and the returned energy from the motor will dissipated into. When the bus voltage is decreased to another certain value, greater than $V_{d c}$, the mosfer switch is switched off.

\section{Mosfet Inverter}

The power circuit used here consists of six power mosfets, each phase has two mosfets as shown in Fig.3. This circuit allows the mosfet switch to be rated close to the maximum supply voltage. This is important where the available switch voltage may be limited. This circuit has three main modes of operation. The first, a positive voltage loop, occurs when both switching devices of the phase are turned on, the supply voltage is connected across the phase winding and the current in the phase winding increases rapidly, supplying energy to the motor. The second of operation is a zero voltage loop. This occurs if either of the two switching devices is turned off while current is flowing in the phase winding. Energy is neither taken from nor retumed to the dc supply minimizing the current ripple rating of the supply capacitor. The third mode of operation is a negative voltage loop. Both of the switching devices are turned off. The current is forced to flow through both freewheeling diodes and the energy is returned from the motor to the supply.

\section{Control And Measuring Circuit}

This circuit, as shown in Fig.2, consists of five parts: a microcomputer, position and speed measuring circuits, a current reference circuit, a logic circuit, and transistors drive circuits. 


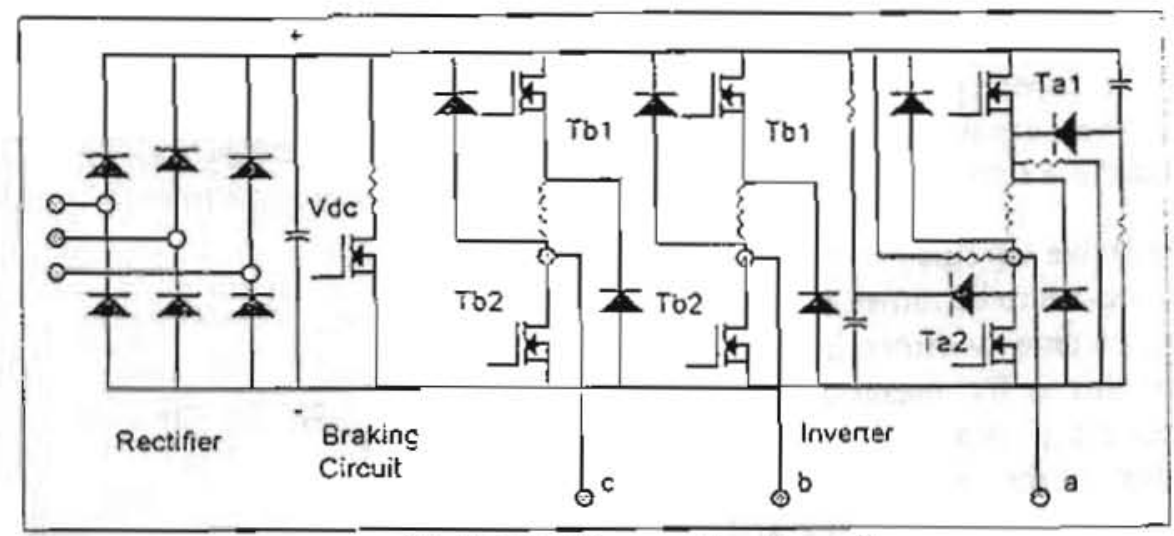

Fig. 3 SRM Power Circuit

\section{A. Microcomputer Control}

It consists mainly of the PC and an interface circuit. This impiements control algorithms to adjust the switching angles in order to give the desired response of the drive and to optimize the efficiency. The interface output control signals are coupled with another signals to control the six power transistors of the power circuit. The feedback speed $\omega_{\mathrm{m}}$ is sensed and scaled in the feedback circuit and applied to the microcomputer control system. Externai inputs to the control system are, the reference speed, the reference direction (both are entered by the keyboard), and the stop signal and the change motor state signai.

\section{B. Position and Speed Circuits}

The switching angles must be counted relative to a reference position. The reference position signal was generated by a shaft position transducer. This consists, as shown in Fig.4, of three optical sensors (SA, SB, and SC) mounted on the motor stator and an interrupting slotted disk, coupled to the motor shaft. Each sensor is mounted at the axis of a stator-phase and monitors the reference position of that phase. The obtained three signals SA, SB, and SC of the optical transducers are manipulated 10 obtain the shaft position. The reference position signal generated, is loaded to the microcomputer interface circuit from which, the speed, direction of rotation, and the inverter drive-pulses are obtained.
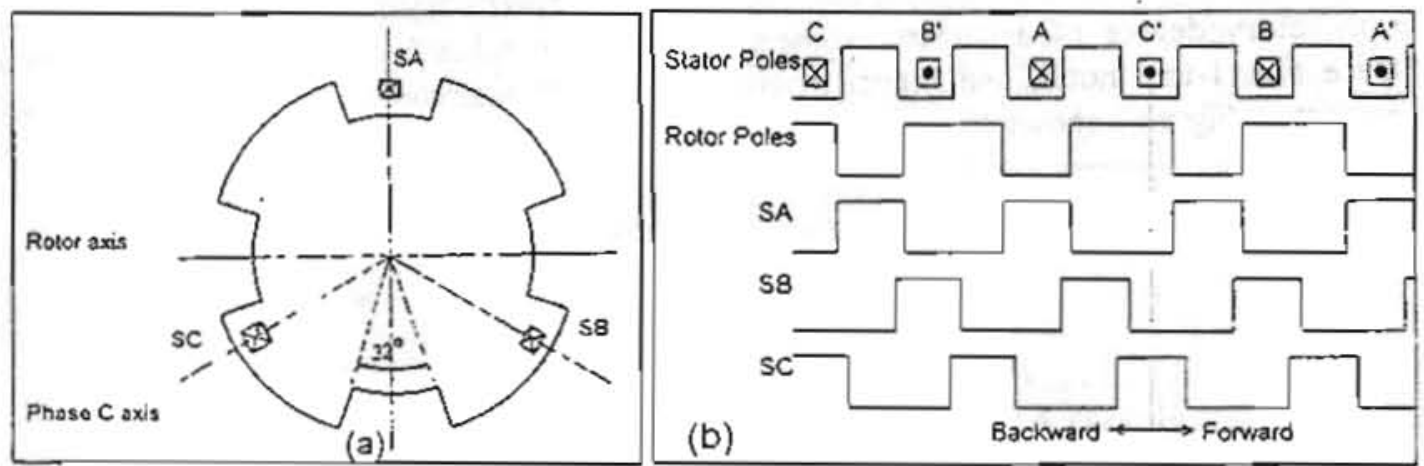

Fig.4 Position and Speed Transducer

\section{Current limiting Circuit}

This circuit is used to limit the current from rising above the motor rated current. It is used as a hysteresis comparator. It sense the phase current and compare it with a reference value. The output signal is a logic signal equals one (High) if the phase current is less than the rated value and equals zero (Low) if the phase current is greater than the rated current value. 


\section{The Logic Circuit}

This is a decoding circuit, it receives the control signals from the microcomputer interface circuit, the outputs of the current limiting circuit and the shaft position output signals and decodes these signals to produce the gate driving signals of the transistors.

\section{E. The Drive Circuit}

For a device to be turned on, a certain charge has to be supplied to the gate to raise it to the desired voltage, whether in the linear region, or in the saturation. Ideally, the best way to achieve this is by means of a voltage source, capable of supplying any amount of current in the shortest possible time. If the device is operated as a switch, a large transient current capability of the drive circuit reduces the time spent in the linear region, thereby reducing the switching losses. Turn-on-time and turn-on-energy can be decreased by increasing the applied drive voltage. Increasing the drain stray inductance decreases turn-on-losses, but increases the turn-off-losses by a far greater amount. The smaller this inductance, the faster the switching time, and the lower the over all energy losses. It is good design practice, therefore, to keep this inductance as small as possible, by appropriate attention to circuit layout.

\section{System Simulation}

\section{Aim of Analysis}

The aim of the following analysis is to get a control strategy with optimal efficiency. The performance of the SRM is carried out including the calculation of the instantaneous phase current, the average torque, and the motor efficiency at constant speed and chosen switching angles $\left(\theta_{o n}\right.$ and $\left.\theta_{c}\right)$. The data required for this analysis are the switching angles ( $\theta_{\text {on }}$ and $\left.\theta_{c}\right)$, the chopping current limits $\left(\mathrm{I}_{\mathrm{cmin}}\right.$ and $\left.\mathrm{I}_{\mathrm{cmax}}\right)$, the $\mathrm{dc}$ voltage value $\mathrm{V}_{\mathrm{dc}}$, the motor speed, and the magnetic characteristics $L(\theta, i)$. As a result from this analysis, a linear relation between the conduction- and switch-en-angles for optimal efficiency is obtained. According this relation the hardware and software of the control system are implemented.

\section{Modeling of SRM}

In the nonlinear analysis of the SRM, the current dependent inductance and the phase resistance are considered. Thereby, the machine performance can be predicted with satisfactory degree of accuracy. Some assumptions are taken here in the nonlinear analysis, these are; 1-the mutual inductance between phases are neglected. 2- the iron losses are also negiected. Figure 5 shows current and inductance variations versus displacement angles.

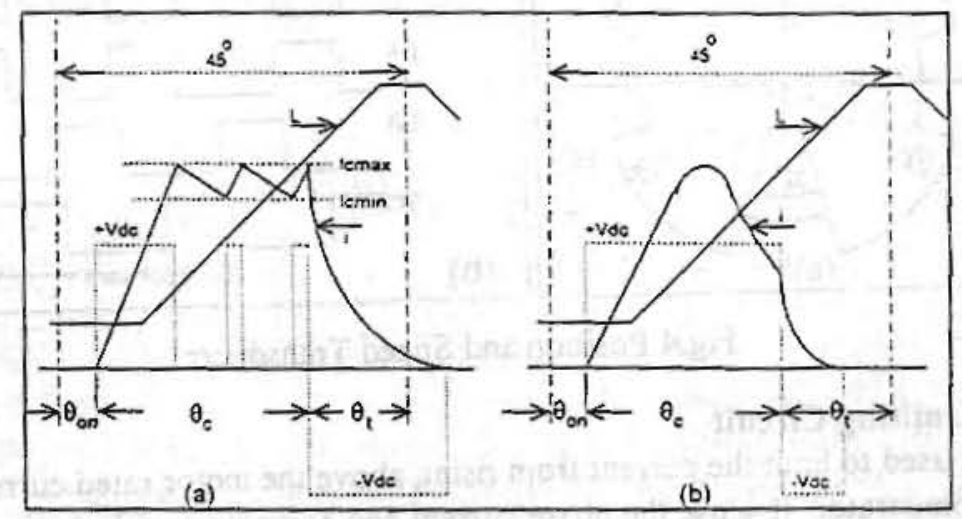

Fig. 5 Phase inductance, current and voltage (a) Chopping mode (b) Single pulse mode 
The voltage equation for a phase winding can be given by:

$$
\pm V=\frac{d \psi(\theta, i)}{d t} \div R_{p} i
$$

where; $R_{p}:=$ phase winding resistance and $\pm V:=$ the phase voltage, and the $亡$ sign are dependent on the state of the electronic switches.

Solving Eq. 3 each time with the proper sign, according to the switching period whether it is 'on' or 'off, the corresponding current waveform can be obtained. Consequently the torque and, in turn, the machine performance can be determined. A numerical solution of Eq.3 makes it an essential demand to prepare the magnetic characteristics of the machine, list of $\psi(\theta, i)$ or list of $L(\theta, i)$ where;

$$
\psi(\theta, i)=L(\theta, i) i
$$

From Eq.4, it is deduced that, any of the two variables $\psi(\theta, i)$ or $L(\theta, i)$ is known, the other variable will be determined at the same phase current value. The algorithm for current calculation taken here, is the time stepping integration of the voltage equation.

$$
\psi(\theta, i)=\int\left( \pm V-R_{p} i\right) d t
$$

The voltage is generally known, being a function of the dc supply voltage and the states of the switches in the controller. At the current rotor position, the phase flux linkage is obtained by integrating Eq. 3 over the previous time step, and an updated value of $i$ must be found from the magnetization data. The procedure will be repeated, and then, the instantaneous phase current will be determined.

The input power $P_{i}$ to the motor is equal to the output mechanical power $P_{m}$ and the power losses $\mathrm{P}_{\mathrm{l}}$ (copper losses). Then;

$$
\mathrm{P}_{\mathrm{i}}=\mathrm{P}_{\mathrm{m}}+\mathrm{P}_{1}
$$

The input power can be calculated as shown in the following relation;

$$
P_{i}=\left(\frac{q p_{t} \omega}{\pi}\right) \int_{0}^{2 \pi / p p_{t} \omega} \pm V . i d t
$$

The power losses can be also calculated from the following equation;

$$
P_{l}=\left(\frac{q P_{r} \omega}{\pi}\right) \int_{0}^{2 \pi / Q p_{r} \omega} i^{2} \cdot R_{p} d t
$$

Then;

$$
P_{m}=P_{i}-P_{i}=T_{3 v} \cdot \omega
$$

From Eq. (9), the average torque $T_{a v}$ is;

$$
P_{i}=\left(\frac{q p_{r}}{\pi}\right) j_{0}^{2 \pi \prime} p_{r} \omega\left( \pm V \cdot i-i^{2} R_{p}\right) d t
$$


So, the efficiency of the motor can also be calculated as follows;

$$
\eta=\frac{P_{m}}{P_{i}}
$$

A block structure of the sequence of the mathematical calculation is shown in Fig.6. The calculation will be carried out over one rotor pole pitch, starts at $\theta=0$ and ends at $\theta=2 \pi / \mathrm{p}$,

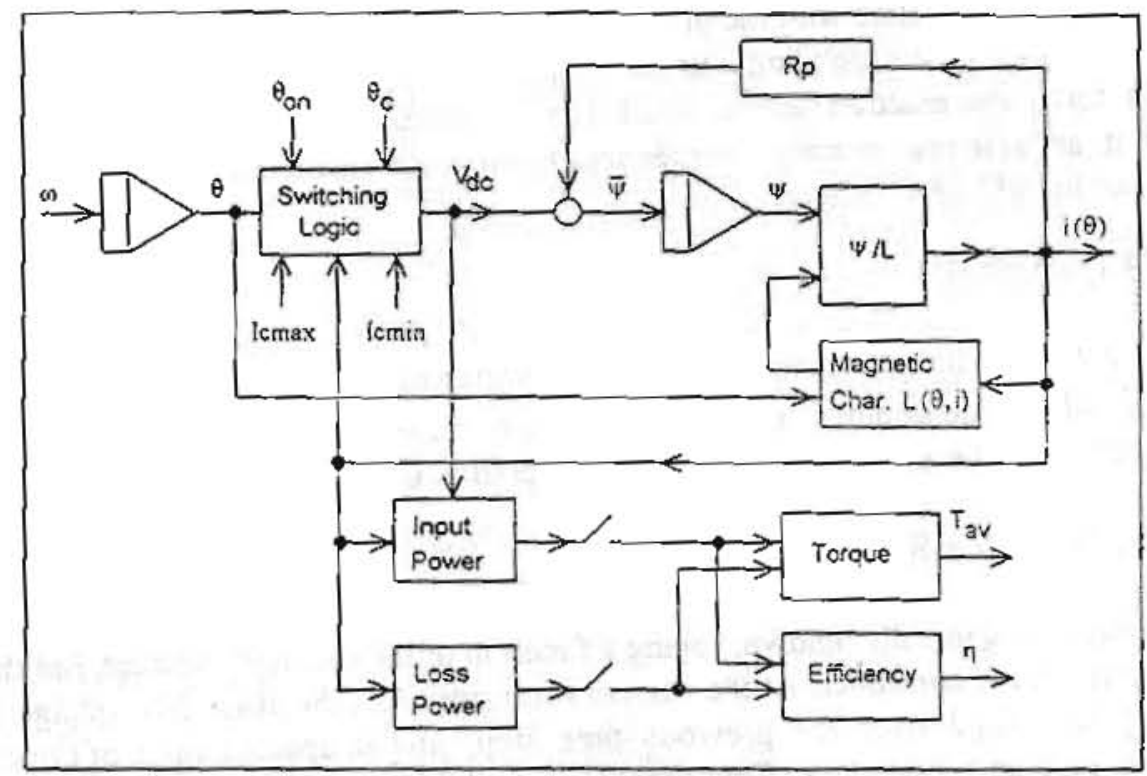

Fig.6 System Simulation

The input variables of the switching-logic block are $\theta_{o n}, \theta_{c}, I_{c m a x}, I_{c m i n}$ and $i$ and gives the phase voltage as output. The phase voltage equals zero in the region of $0<\theta<\theta_{\text {on }}$, at the instant when $\theta=\theta_{\text {on }}$ the phase voltage will go up to $\div V_{d c}$. In the region of $\theta_{o n}<\theta<\theta_{c}+\theta_{o n}$, the phase voltage still equals $\div V_{d c}$ as long as the phase current is less than the maximum limiting value. If the phase current reaches the maximum limiting value $I_{c m a x}$ the voltage will go down to zero, it remains zero until the phase current becomes less than the minimum limiting value $\mathrm{I}_{\mathrm{cmin}}$, then the voltage go up again to $+\mathrm{V}_{\mathrm{dc}}$, as shown in Fig.5. At the instant when $\theta$ is greater $\operatorname{than} \theta_{o n}+\theta_{c}$ the voltage will go down to, $-V_{d c}$ until the phase current equals zero.

The winding resistance voltage drop $i R_{p}$ is subtracted from the output of the switching logic block, this give the value of the rate of change of the flux linkage $d \psi / d t$. The output of the summing point is integrated to produce the flux linkage $\psi$, and then the flux linkage is divided on the inductance value to give the phase current value $i$. The inductance value is selected from the stored magnetic characteristics $L(\theta, i)$ shown in Fig. 7 according to the values of both $\theta$ and phase current $i$ from the previous step of calculation. The inductance between these curves can be calculated by linear interpolation. As the instantaneous current is known, the average torque and efficiency will be calculated easily as shown in Eqs. (3-5, 6, 7, 8, 9).

The algorithm of the calculation is the base of the computer program designed to calculate the motor performance. The computer calculation is carried out by using a simulator program called TUTSIM. This ready program is an analog computer simulation program. The outputs 
of this algorithm are the phase current at each step of calculation and, the average torque and efficiency at the end of the calculation cycle.

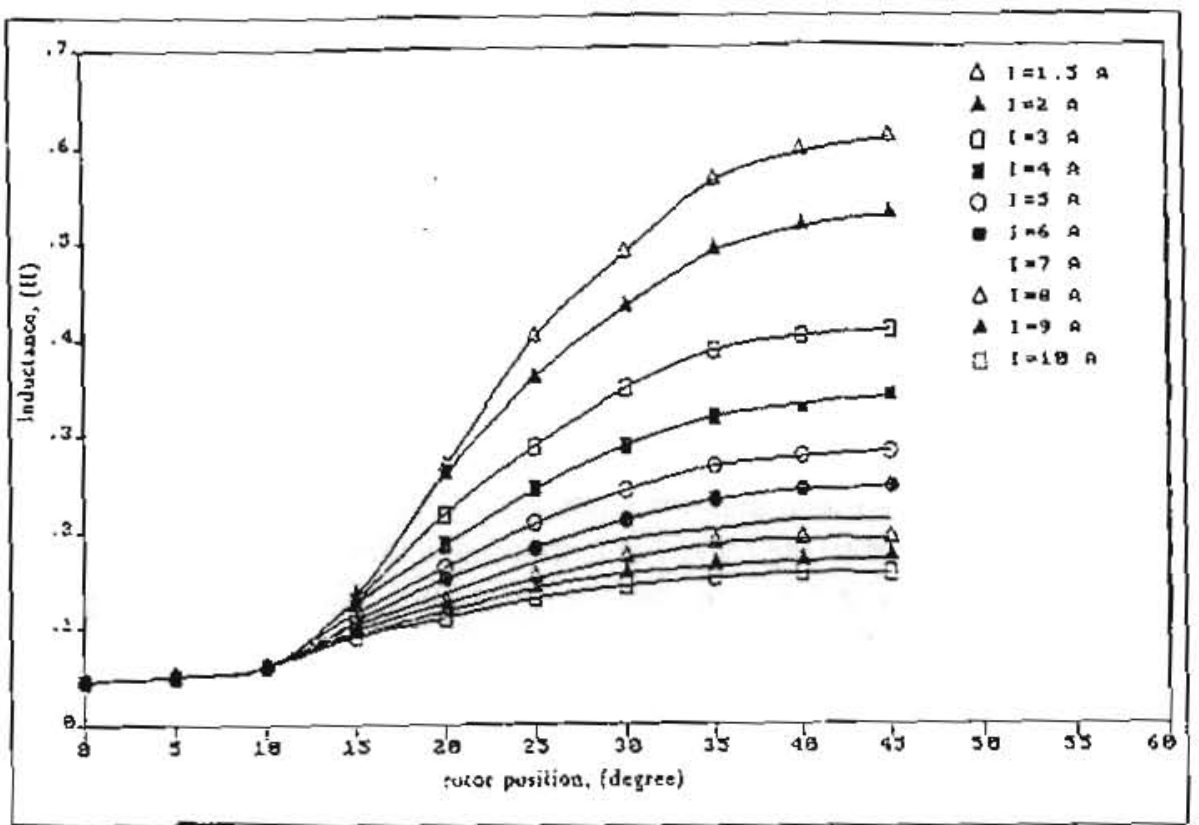

Fig. 7 Measured Inductance variation versus rotor position and current as parameter

The SRM model is tested for the speed range starting from $200 \mathrm{rpm}$ with step change of 200 rpm up to $1200 \mathrm{rpm}$ where rated speed is $800 \mathrm{rpm}$. Only performance curves for 200,800 , and $1200 \mathrm{rpm}$ are given here. The following points were noted from the obtained figures:

\section{A. Normal Operation}

1. At low speed, the motor is able to give output torque greater than the rated torque. This is, because the motor speed is low so, the voltage forces the phase current to reach the maximum chopping current level value. Therefore, at low speeds, the rated torque can be taken from the motor at a small conduction-angle and advancing the switch-on-angle to the position of the beginning of rising inductance region. Then, the phase current is prevented from fast rising. The chopping frequency is reduced and therefore the inverter efficiency is increased and also, the copper loss is reduced and so, the motor efficiency is increased.

2. The efficiency curves of low conduction-angles have wide ranges of switch-on-angle those give approximately the maximum efticiency, and these ranges are decreased in the direction of increasing conduction-angles. This is, because at low conduction-angle value, the current rises and also decays to zero at the region of increasing inductance so, the peak value of the current will be small, and the copper losses will be reduced. Also, the efficiency curves decay rapidly especially at low conduction-angles.

3. The same torque car. be developed for a higher speed with larger conduction-angle than that at lower speed. This is due to the fact of the higher the speed, the little the chance of rising of the phase current. The maximum torque of each curve is still occurred at the 
same switch-on angle, but it less than that at lower speed. Also the maximum torque is dependent on the maximum chopping current level.

4. The efficiency in general increases with the speed for the same switch-on-angle and conduction-angle.

5 The relationship between the conduction-angle and the switch-on angle at any torque value can be represented by a straight line. So, the switching period can be defined by knowing the conduction-angle only.

6. The amount of delay-angle, at which the peak torque occurs, is proportional to the motor speed, as the motor speed is increased the delay must be increased. Also, the motor is still able to develop the maximum allowable torque. This is because the motor speed is still blow the rated speed.

7. At rated speed, the rate of decay of the torque curves with respect to the switch-on angle is very high compared with the lower speeds. This is because, at high speed, if the switchon angle is advanced to the region of increasing inductance, the current will be prevented to be built up rapidly and to give the required torque. This is increased as the motor speed is increased. The motor at this speed does not able to deliver the maximum allowable torque and it gives the rated torque at the rated conduction-angle and so, it gives the designed rated power at the rated speed.

8. The maximum allowable torque equals ( $16 \mathrm{NM}$ ), the rated torque reaches (12 NM), and the rated conduction-angle is $\left(30^{\circ}\right)$.

9. If the running speeds are greater than the rated speed, therefore the single pulse mode is valid here and the chopping does not occur at these speeds. So, at the rated conductionangle, the motor does not able to deliver the rated torque. As the speed is increased the motor developed torque is decreased. At the rated speed and lower, the motor develops the rated torque and greater but at speeds above the rated, the output torque is decreased as the motor speed is increased. So, the motor çan be used in a drive system to develop a constant torque at speeds below the rated speed (constant torque region), and a constant power at speeds above the rated (constant power region).

The motor efficiency in general is greater than that in the case of the lower speeds. The linear relationship between the switch-on angle and the conduction-angle is still also valid. 


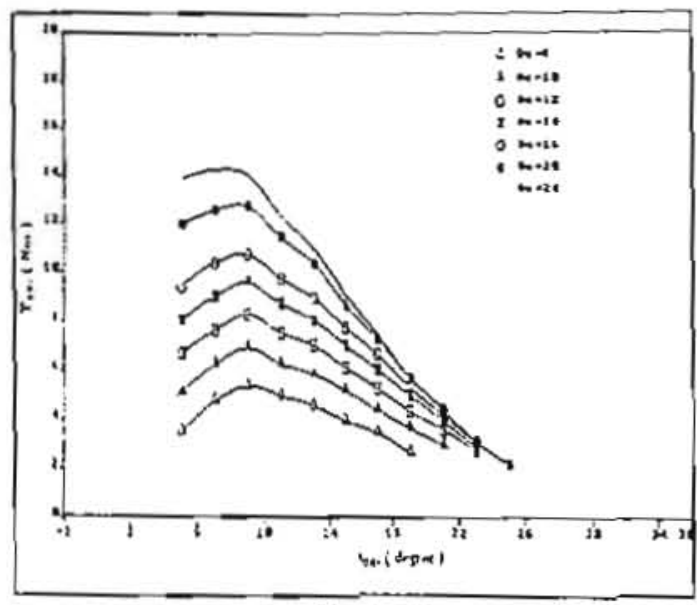

Fig. 8 a

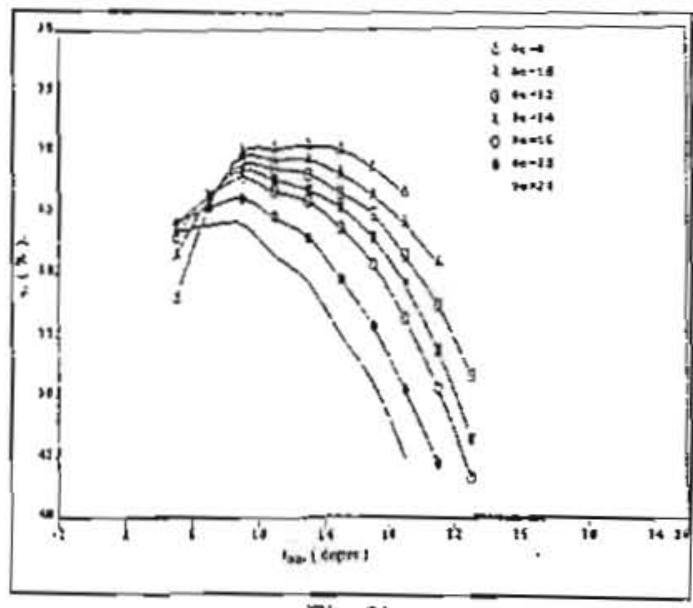

Fig. 80

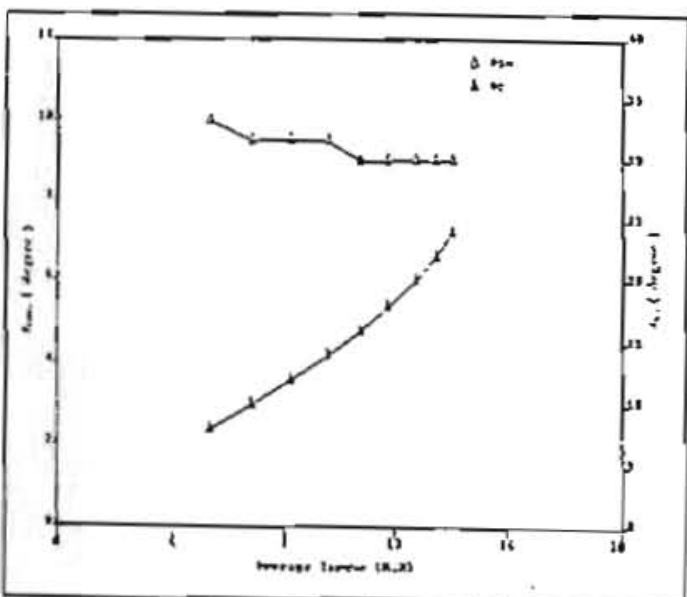

Fig. $8 \mathrm{c}$

Fig.\$ Performance curves for $200 \mathrm{rpm}$

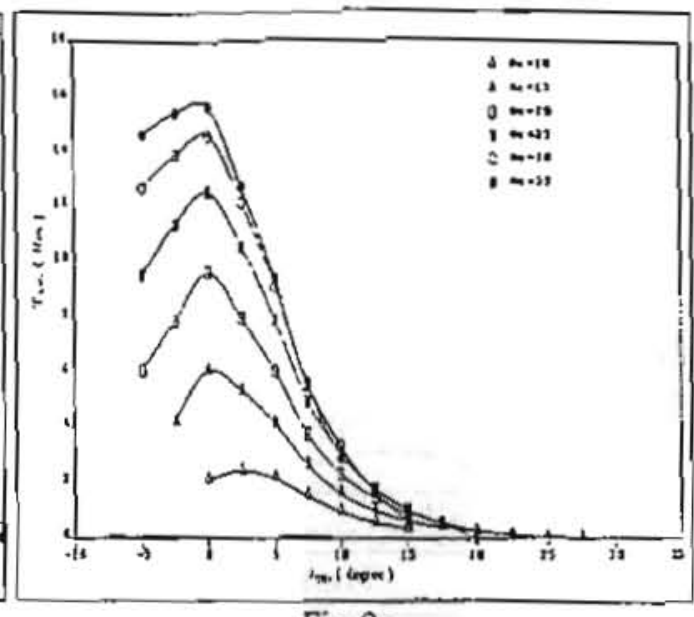

Fig.9a

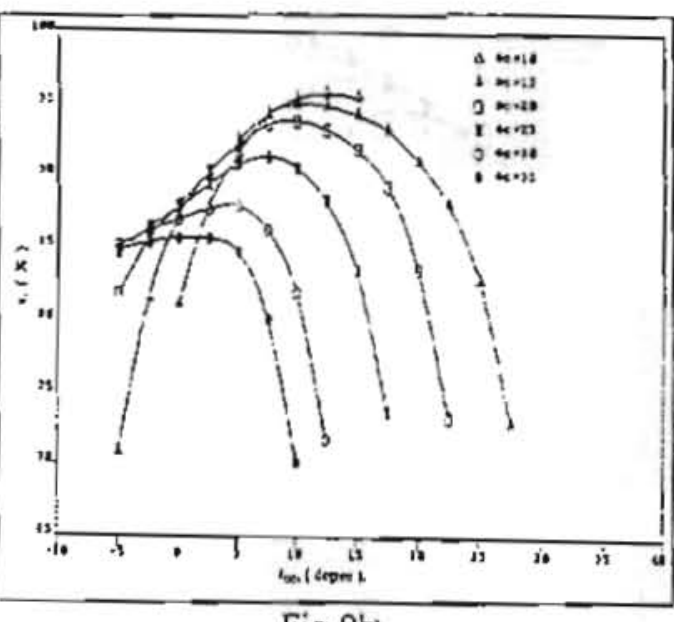

Fig. $9 b^{\circ}$

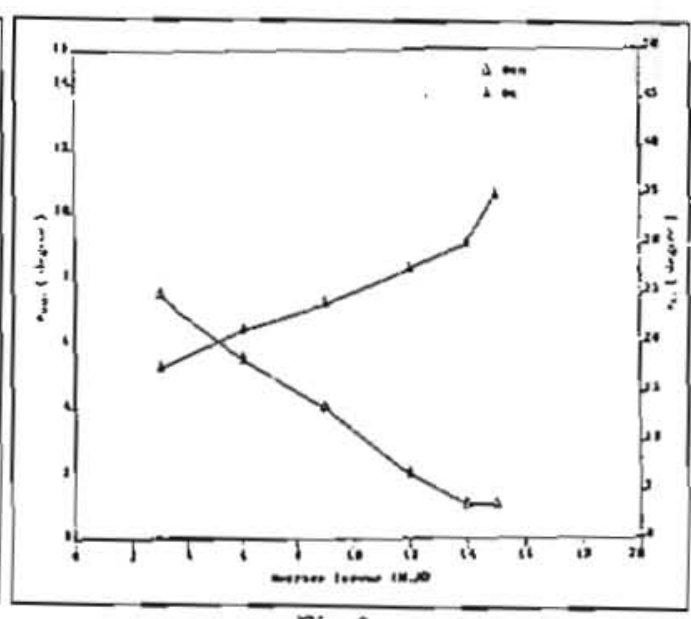

Fig.9c

Fig. 9 Performance curves for $800 \mathrm{rpm}$ 


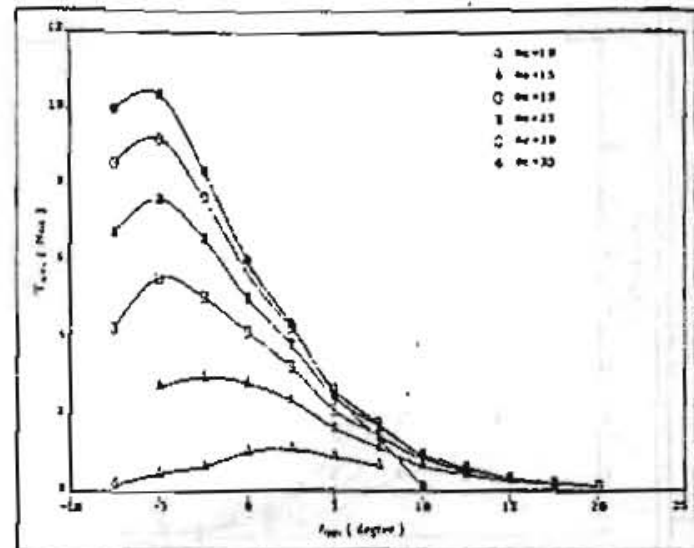

Fig.10a

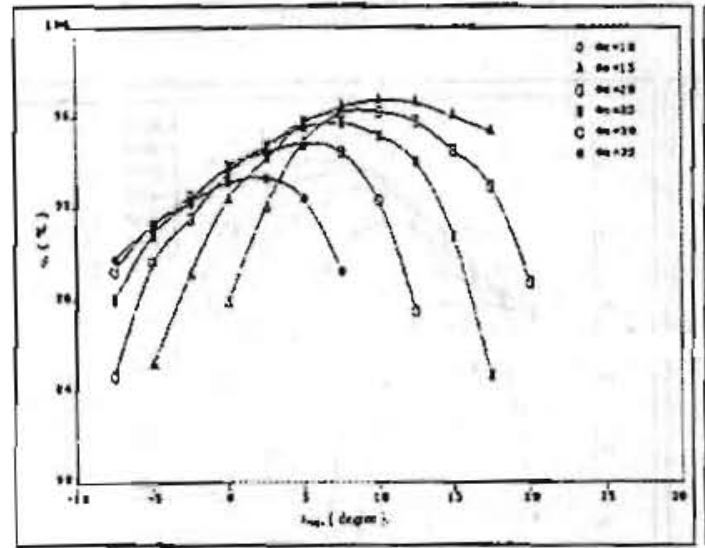

Fig. 10b

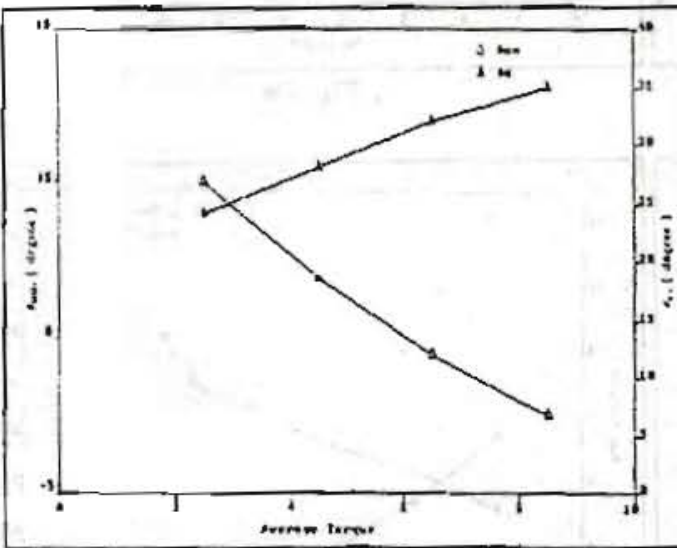

Fig. 10c

Fig. 10 Performance curves for $1200 \mathrm{rpm}$

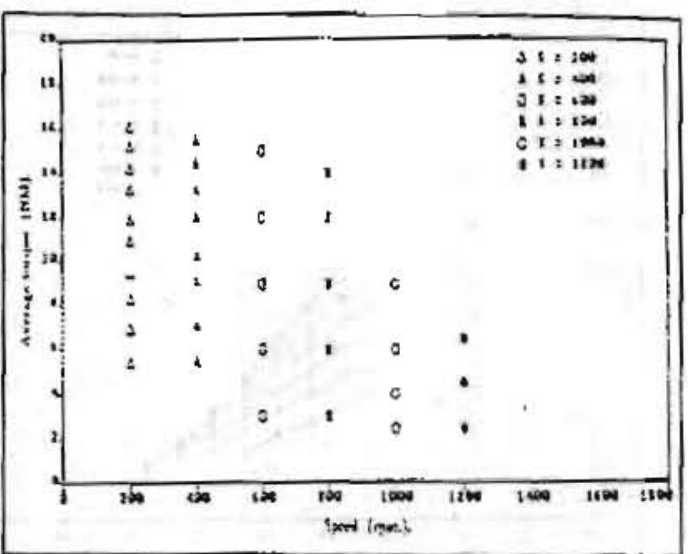

Fig.11a

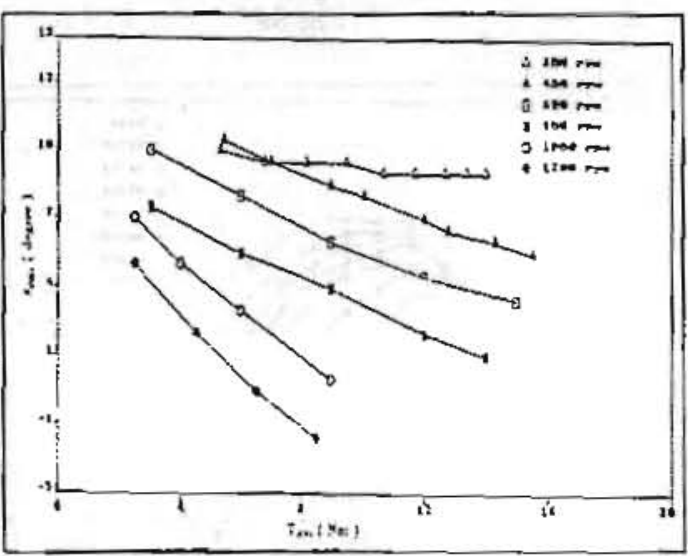

Fig.11b

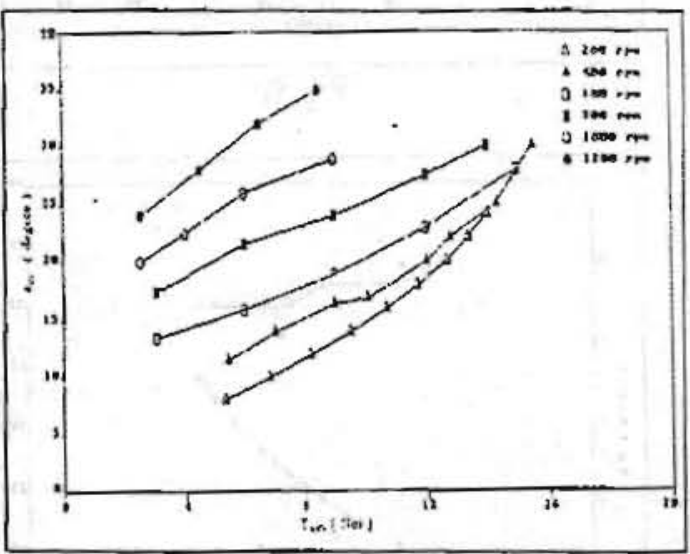

Fig.11c

Fig.11 Optimal Operation

\section{B. Optimal Operation}

Figure (11.b) shows the optimal switch-on-angle $\theta_{\text {on }}$ versus the average torque with motor speed as parameter. We note that, at certain torque value, the switch-on-angle is increased as the speed is decreased. This agrees with the fact that, the switching-on angle is properly delayed even to the rising region of the inductance. It will be effective not only to limit the current, but also to meet the needs of the current required by the given torque and also the system efficiency can be improved. At low speeds, the chance of the current to be increased 
to the chopping level is very large and this will be limited by advancing the switch-on angle to limit the current and gives the same torque. Figure ( $(i \mathrm{ic})$ also shows the optimal conductionangle $\theta_{c}$ versus the load torque with motor speed as parameter It will be seen that, the conduction-angle is increased as the motor speed is increased at certain torque value.

\section{Control Strategy And Efficiency Optimization}

An imporant characteristic of the SRM is its inherent nonlinearity. The inductance of the magnetic ciscuit is a nonlinear function of the rotor position and the phase current. Because of these nonlinearities, drive optimization are performed numerically.

As weil known, the SRM speed can be controlled by varying one or all of the control variables; chopping current level $I_{c h o o}$, switch-on angle $\theta_{\text {on }}$ and the conduction-angie $\theta_{C}$. Based on the chosen control strategy and the measured parameters, $L(\theta, i)$ and the motor winding resistance of the motor, the mathematical models of both loiv speed chopping operation and high speed single puise operation are built corresponding to the power circuit topology. During steady state operation at low- and high speeds, the current waveform, the average torque and the motor efficiency are resolved. Based on these calculated performance, the switching angles for obtaining the highest efficiency can be chosen.

\section{Control Strategy}

It is recommended that, control variables should be as less as possible in a control system in order to simplify control law and control circuit. Many control strategies were carried out in previous works, and it is obtained that the control strategy is differed from work to another. The control variables were taken in each work can be concluded into;

I- $I_{\text {chop }}, \theta_{\text {on }}$ and $\theta_{c}$ by Torry [9] and Cai Wei. [11]

2- the mean control variable was taken by Bose [6] and A.R. Oza [10], is $I_{\text {chop }}$

3 - the switch-on angle $\theta_{\text {On }}$ is taken by both Goa [7] and Corda [8]

In this paper, the switch-on angle $\theta_{O n}$ and the çonduction-angle $\theta_{c}$ are taken as control variables and the chopping current $I_{\text {chop }}$ will be maintained at the maximum rated current of the motor. So, the control strategy depends on the vanation of both the switch-on angle $\theta_{o n}$ and conduction-angle $\theta_{c} 10$ give the desired torque and speed with maximum efficiency.

At any load torque and speed, the motor must be operated at switching angles according to that given in figures $(11 \mathrm{~b}, 11 \mathrm{c})$ to obtain optimal efficiency operation. So, this curves must be stored in the motor control system if you want to operate it at optimal efficiency. This is very difficult so, it is desired to get a simplified expression.

As seen from Fig.11c, the conduction-angle is directly proportional with the average torque, so a curve can be plotted showing the optimal switch-on-angle versus the conduction-angle with motor speed as parameter. Such curve is shown in Fig.12a for all the speed range and Fig. $12 \mathrm{~b}$ for speed above $200 \mathrm{rpm}$. It is clear that, the operating points can be implemented by a straight line with minimum error. The equation of this straight line is given by;

$$
\begin{aligned}
\theta_{\text {on }} & =16.5-0.5 \theta_{c} & \text { for } \omega & >200 \mathrm{rpm} \\
& =9^{\circ} & \omega & <200 \mathrm{~mm}
\end{aligned}
$$


Therefore the control system must be arranged, so that output of the controller is the conduction-angle because it is proportional to the motor torque. By knowing the conductionangle value, the switch-on-angle can be calculated according to Eq.12. Practically, only the equation of the straight line is used for calculating the switch-on-angle for all speeds from zero to the maximum value with sacrificing the optimality at low speeds.

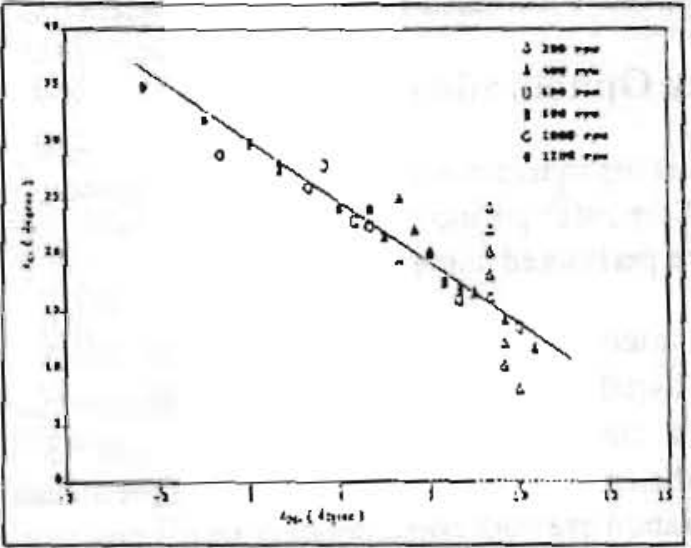

(a) Total speed range

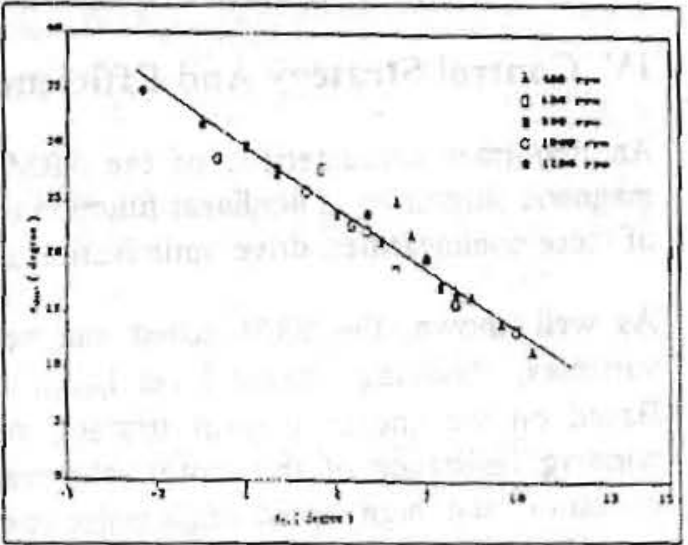

(b) $\omega \geq 200 \mathrm{rpm} \geq 1200 \mathrm{rpm}$

Fig.12 Optimal switching angle

From Eq.12, the control variables are reduced to only single control variable, by knowing one of these variables the other can be determined. The independent control variable is the conduction angle $\theta_{c}$ and the dependent is the switch-on-angle $\theta_{\text {on }}$

According the above analysis, the control scheme of Fig. 2 can now be simplified to the block diagram shown in Fig.13. It consists of PI controller, zero order holder, a lookup table for the conduction- and switch-on-angles, and the SRM. The zero holder gives an output signal proportional to the conduction-angle $\theta_{c}$ where the output of the lookup table is the corresponding switch-on-angle. Both angles control the performance of the SRM.

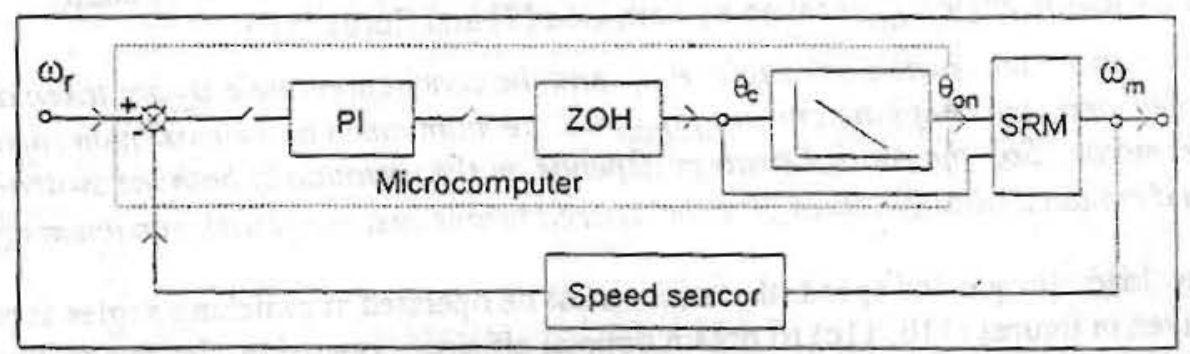

Fig. 13 Control Block diagram for SRM

\section{Efficiency Optimization}

The ratio of energy converted (EC) to energy input must be as high as possible, to maximize the system efficiency. The EC of the system can be greatly increased by more effective use of the input energy (recovering some of the stored magnetic energy to be converted as mechanical output). There are two methods to recover the returned energy of the SRM, the first, is the normal chopping and the second, is the freewheeling method. For normal chopping, both switches of the phase are opened and closed together. When they are opened the stored magnetic energy causes the current to flow through the diodes, thus appiying $-V_{d c}$ to the winding. The flux ramps down and energy is returned to the suppiy. When 
freewheeling is employed, only one switch is opened (except at the end of the conduction period) and the current circulates, with zero applied voltage, through one diode and the closed switch. The flux decays because of winding resistance and device voltage drops, which are smail. Thus, when the supply is off, most of the stored magnetic energy is converted to mechanical output, instead of being returned to the supply. The rise time of the current is the same with or without freewheeling, but the decay rate is slower with freewheeling, as the impressed voltage is then zero $[4,5]$. It is obtained that the energy circulation does not occur in the case of freewheeling and then, the EC is much higher. Also, the frequency of chopping is lower with than without freewheeling, so, the switching losses is reduced. The freewheeling method is the most efficient method to recover the stored magnetic energy. Thus, it will be applied in this work.

\section{Results and Recommendations}

The SRM drive was built and operated at wide range of speeds and torque loads. Comparison between measured and the calculated variables are carried out. The SRM drive was coupled with an inertia load and a dc machine as a torque load. The calculated performance are the output average torque, the motor efficiency and the instantaneous phase current. The measured yariables are the phase current waveform, the phase voltage waveform and the output potver and torque of the dc machine.

Figure 14 shows the measured phase current waveform and drain to source voltage at speed equal to $800 \mathrm{rpm}$, conduction-angle $\theta_{c}=29.5^{\circ}$, switch-on angle $\theta_{o n}=1.7^{\circ}$ and the supply voltage equal to 172 volt. The output power from the dc machine at this operating condition is equal to $177 \mathrm{~W}\left(\Upsilon_{\mathrm{av}}=2.11 \mathrm{NM}\right)$. Therefore, the output power of the SRM equals to the output power of the dc machine plus the friction losses, the stray losses of the dc machine and the armature copper loss of the dc machine, therefore, it equais to $280 \mathrm{~W}$.

Figure 15 shows the calculated phase current and voltage at the same condition of the operating point in Fig.14. The calculated output power from the motor is equal to $316 \mathrm{~W}$ $\left(\mathrm{T}_{\mathrm{av}}=3.77 \mathrm{NM}\right)$.

The comparison between the measured and the calculated waveforms in Figs. $(14,15)$ shows that, there are a great concordance between the measured and caiculated current waveforms. The peak of the measured current waveform is equal to $4.6 \mathrm{~A}$ and for the calculated is $4.7 \mathrm{~A}$. The measured phase current at switch-off instant is equal to $2.2 \mathrm{~A}$ and the measured at the same position is equal to $2.4 \mathrm{~A}$. The comparison shows that, the calculated performance can be accepted to be a measure of the actual performance of the motor with a little deviation.

Figure 16 shows the measured phase current waveforms and the drain to source voltage at speed equal to $800 \mathrm{rpm}$, conduction-angle $\theta_{c}=27.70$, switch-on angle $\theta_{o n}=1.70$ and the supply voltage equal to 200 volt. The output power from the dc machine at this operating condition is equal to $251 \mathrm{~W}\left(\mathrm{~T}_{\mathrm{av}}=3 \mathrm{NM}\right.$ ). The measured output power from the SRM will be equal to $366 \mathrm{~W}$.

Figure 17 shows the calculated phase current and voltage at the same condition of the operating point in Fig.16. The calculated output power from the SRM is equal to $411 \mathrm{~W}$ $\left(\mathrm{T}_{\mathrm{av}}=5.4 \mathrm{NM}\right)$. The comparison between the calculated and measured phase current waveform shows that, there is minimum deviation between them also at this operating point. 


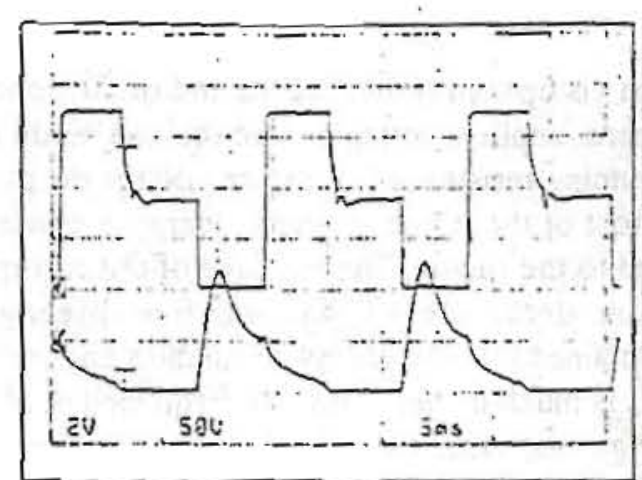

Fig.14

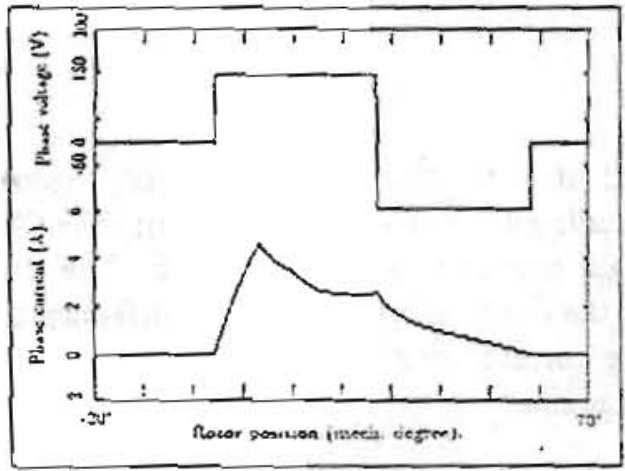

Fig. 15

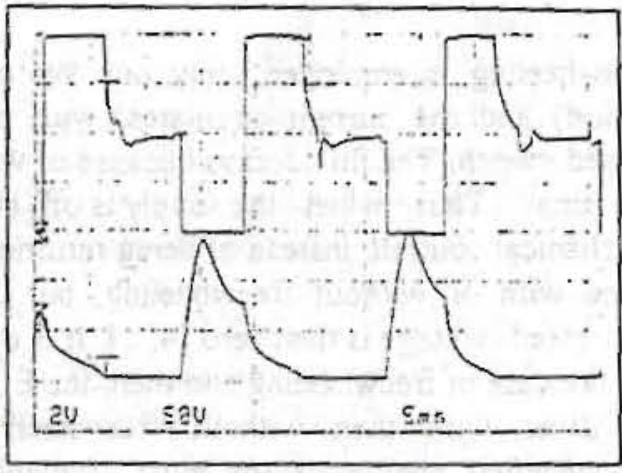

Fig.16

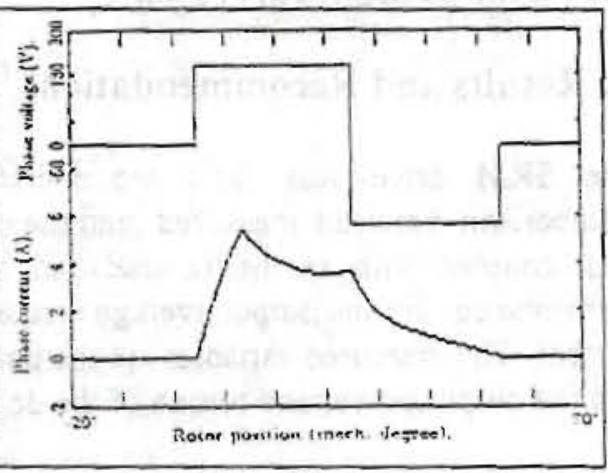

Fig.17

Figure 18 shows the measured phase current and voltage waveforms at speed equal to 800 rpm, conduction-angle $\theta_{c}=32^{\circ}$, switch-on angle $\theta_{o n}=-1^{\circ}$ and the supply voitage equal to 210 volt. The output power from the motor is greater than that in the previous cases due to greater voltage and conduction-angle. So, the phase current is built up rapidly to reach the chopping level (here equal to $6 \mathrm{~A}$ ). The output power from the d.c machine equals to $384 \mathrm{WW}$ $\left(\mathrm{T}_{\mathrm{av}}=4.6 \mathrm{NM}\right)$. The measured output power equals to $536 \mathrm{~W}$.

Figure 19 shows the calculated phase current and voltage at the same condition of the operating point in Fig.18. It is seen that, the current reaches the chopping level, and the chopping is occurred one cycle only, this is happen in the measured and calculated waveform. The calculated output power from the motor is equal to $540 \mathrm{~W}\left(\mathrm{~T}_{\mathrm{av}}=6.56 \mathrm{NM}\right)$.

Figure 20 shows the measured phase current and voitage at heavy load and high voltage approximately equal to the rated voltage of the motor and also the phase current is approximately equal to the rated. These measured waveforms are at speed equal to $896 \mathrm{rpm}$, conduction-angle $\theta_{c}=32^{\circ}$, switch-on-angle equal to $\theta_{o n}=-1^{\circ}$ and supply voltage equal to 250 volt. The measured output power from the dc machine at this operating point equals to $789 \mathrm{~W}$ $\left(T_{a v}=8.4 \mathrm{NM}\right)$. So, the measured output power from the SRM equals to $1089.7 \mathrm{~W}$.

Figure 21 shows the calculated phase current and voltage at the same operating point of Fig.20. It is seen that the shape of the calculated waveform has approximately the same shape of the measured phase current with little deviation. The calculated output power from the motor equals to $1006.28 \mathrm{~W}(\mathrm{~T}$ av $=10.7247 \mathrm{NM})$.

Figure 22 shows the measured phase current and voltage at speed equals to $612 \mathrm{rpm}$ with moderately large load and the chopping current levei is $6 \mathrm{~A}$ approximateiy. The conduction- 
angle equals to $32^{\circ}$, the switch-on angle equals to $-1^{\circ}$. The bus voltage equals to 210 volt. Due to this high voltage and moderately low speed the current has the chance to be built up rapidly to reach the chopping level. The chopping is occurred at the beginsing of the switching period by two chopping cycles and tends to repeat this at the end of the switching period. The measured output powver from the dc machine at this operating point equals to $375 \mathrm{~W}$ (Tav=5.842NM). So, the output power from the SRM equals to $548 \mathrm{~W}$.

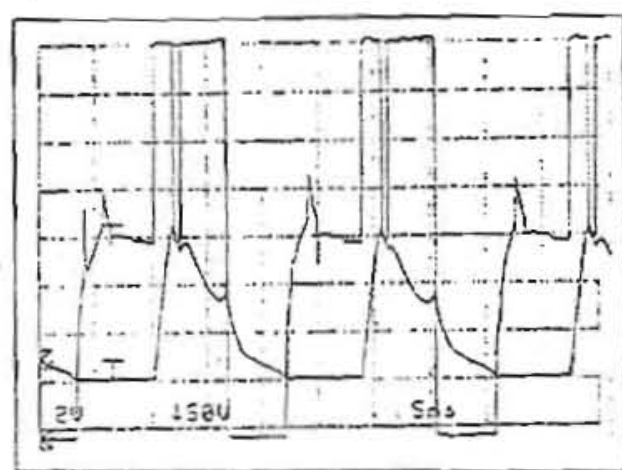

Fig. 18

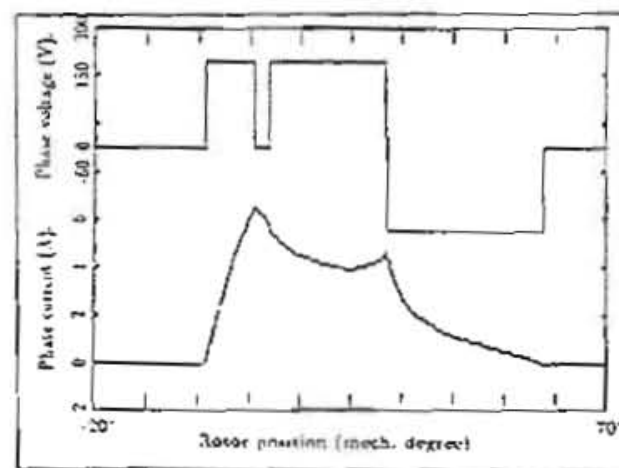

Fig. 19

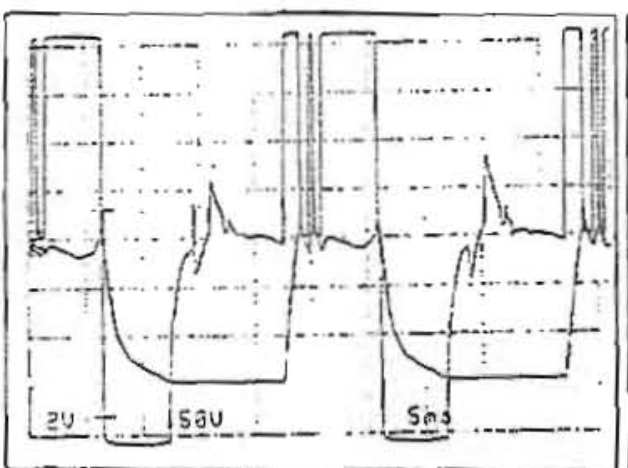

Fig.22

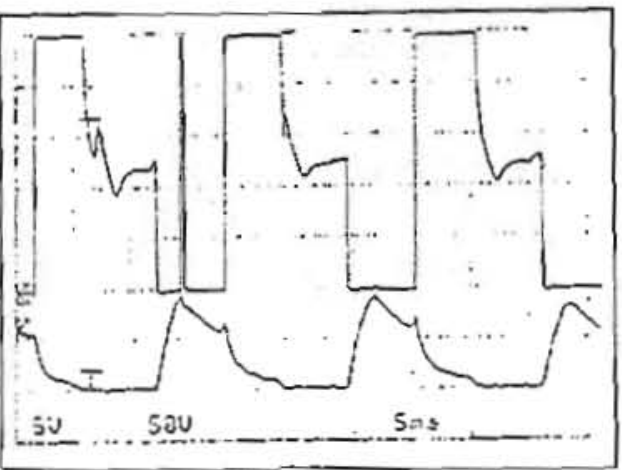

Fig. 20

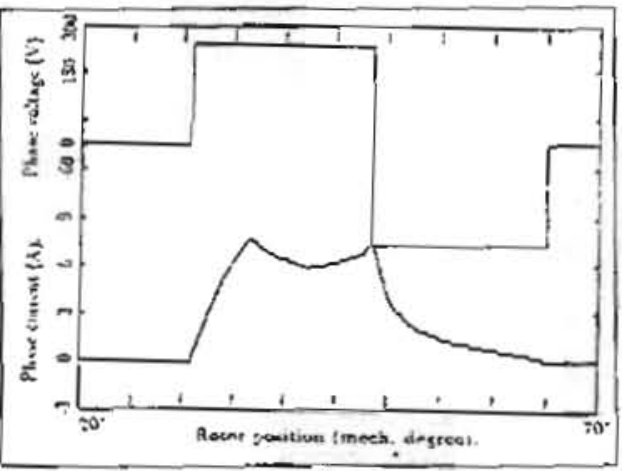

Fig.21

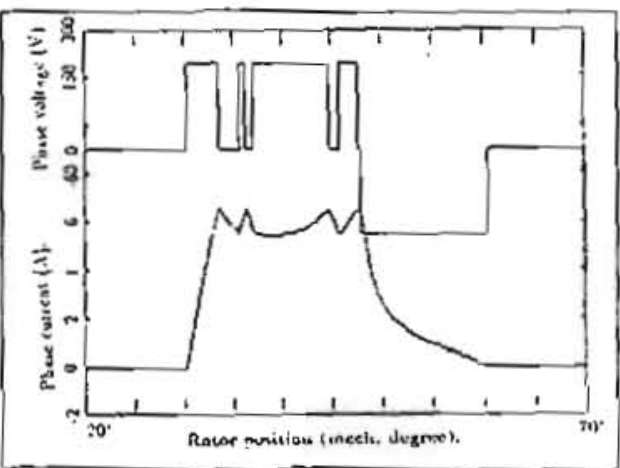

Fig.23

Figure 23 shows the calculated phase current and voltage at the same operating point of Fig.22. It is seen that, the calculated phase current waveform do the same two chopping cycles at the beginning of the switching period as the measured waveform but it makes another chopping cycle at the end of the switching period. This deviation is considered smal! because the measured waveform tends to be chopped at the end of the switching cycle also. The calculated output power from the motor equals to $572 \mathrm{~W}$ ( $\mathrm{T}_{\mathrm{av}}=8.927 \mathrm{NM}$ ). 
The above comparison between the measured and calculated performance at different operating points shows that, there are a great concordance between them. Therefore, the calculated results can be taken as a good reference to understand the motor performance and it has a good accuracy to reflect the motor performance. So, the relationship between the conduction-angle and the switch-on angle to obtain the optimal efficiency operation (Eq.12) has a great confidence to be implemented by the control circuit to give the required optimal operation.

\section{CONCLUSION}

A complete closed loop control system of the SRM drive has been built in the laboratory and experimental investigation have been established. It is designed to be operated in four quadrant at optimal efficiency operation. The complete system

The motor speed and torque are controlled by controlling the switch-on angle and the conduction angle and by maintaining the chopping current level equal to the rated current of the motor. To obtain the optimum combinations of the switch-on angle and the conduction angle, a computer program was designed to solve the motor equivalent circuit and to calculate the motor performance by using software program called TUTSIM [12]. It is obtained from the calculated performance that, there are a simple relationship between the switch-on angle and the conduction angle to give optimurn efficiency operation with the chosen control strategy. The comparison between the calculated results and the measured are carried out and show that, there is a great concordance between them.

The implementation of the control circuit is carried out and satisfied. The control functions include feedback speed control with speed loop, starting and position synchronized angle control. Because of the critical timing requirement, the angle control is implemented with dedicated digital hardware. The feedback speed is measured by using a shaft position sensor mounted on the shaft of the motor. A PI controller is used to improve the system stability and to eliminate the steady state speed error. The controller action is implemented by using a microcomputer system based on the 8086 assembly language. A simple interface circuit has been built for data transfer and also to impiement the digital angle control circuit.

\section{REFERENCES}

[1] Mohamed Mahasen Mostafa El-Sersawi., " Analysis and experimental investigations of switched reluctance machines. ", Ph. D. Thesis, Mansoura university, Egypt, 1989.

[2] M. S. Rashed Mohamed., "Optimum Operation Of Switched Reluctance Motor", M.Sc. Thesis, Mansoura Faculty of Engineering, Elect. Power and Machines Dep. 1993.

[3] P. J. Lawrenson, et al., "Variable speed switched reluctance motors ", IEE Proc., Vol. 127, Pt. B., No. 4 (1980).

[4] J. M. Stephenson, et al., " Torque production and energy circulation in idealised current fed switched reluctance motors ", ICEM Conf., ( 1988).

[5] J. M. Stephenson, M. A. El_khazendar, " Saturation in doubly salient reluctance motors ", IEE Proc., Vol. 136, Pt $\bar{B}$, No. 1, January ( 1989 ).

[6] Bimal K. Bose, et al., "Microcomputer control of switched reluctance motor ", IEEE Ind. Appi., Vol. IA-22, No. 4, July/August ( 1986).

[7] Gao Chao, Xiao Haibing, " Direct digital control of switched_reluctance drive ", BICM paper, Aug., ( 1987 ). 
[8] Corda, 1., et al., " Phase locked loop control as inherent feedback control of switched reluctance motor ", ICEM Conf., (1988).

[9] Prof. D. A. Torrey, Prof. J. H. Lang, " Optimal efficiency excitation of variable_reluctance motor drives", IEE Proc., Vol. 138, No. 1, January (1991).

[10] P. Materu, et al., " steady state anaiysis of the variable speed switched reluctance motor drive ", LECON Conf., ( 1987 ).

[11] Gai Wei, Li Jun, Yuan Jing_an, Shi Nai, 'Mathematical model and dynamic analysis on SRD used new main circuit of one switch element each phase", ICEM Conf., London, september 1992.

[12] TUTSTM IBM PC/XT/AT version 4, distributed by Applied $i$ in USA and Canacia, Applied i, 200 california Avenue Palo Alto, CA 94306. 